\title{
Time for voices to be raised
}

\section{Scientists must become more involved in controversial public debates.}

\section{Derek Burke}

Attitudes to genetically modified (GM) foods and organisms so far have tended to be black and white - GM is either all good or all bad. Despite guidance from scientists (see http:// www.dti.gov.uk/ost/ostbusiness/index.htm), media coverage in the United Kingdom is best captured by the phrase 'Frankenstein food'.

What should scientists do about issues such as GM foods where there is widespread resistance to the technology, clearly arising from very deeply felt convictions, some stemming from concerns that lie outside science?

\section{How society uses science}

I believe we must now become much more involved in public debates on how our society uses science and technology to create wealth and a better quality of life. Otherwise, science will become increasingly marginalized. I believe, too, that we scientists must become much more sophisticated about our relationship with the public, our response to pressure groups, and especially our dealings with the media in the following ways.

First, we should not assume that when we explain what we are doing, the public will always agree with us. Scientists and the public often work with different value systems: for example, not every scientific discovery is accepted as being good for society, to take nuclear power and the value of animal experiments as just two instances.

Second, we need to be much clearer about the complex area of risk and risk perception. This is not objective: different risks are weighted differently by different groups in society (the contrast between US and European attitudes to GM technology is a case in point). Risk decisions use judgement as well as evidence; policy decisions often have to be made before all the relevant facts are available, for example where there is a publichealth concern, as in the cases of BSE and, currently, mobile phones. Changes in societal attitudes have undermined the role of the 'trusted scientist' as a respected source of advice. Others have to be brought into the decision-making, with the resultant problem that everyone wants to be consulted but not everyone can be involved.

Third, how should scientists handle the kind of storm that erupted last year over Arpad Pusztai's claims, subsequently found to have no scientifically credible foundation (see Nature 401, 731; 1999), of damage caused to rats' guts by GM potatoes? Who should respond to comments by media interviewers such as: "So the British public are to be treated as unsuspecting guinea-pigs once again"? Not retailers, who have been quick to sacrifice GM food products rather than lose market share. Not individual companies: Monsanto's brief press campaign was unsuccessful. The public debate is being left, by default, in the hands of scientists.

There are signs that we are learning how to form a constructive dialogue with the public. A conference in Edinburgh in February included representatives from at least 14 developing countries and all major 'green' groups. It achieved a crystallization into points of agreement, points of disagreement, and points where knowledge is currently lacking. There is surprisingly widespread acceptance that the issues are not all black

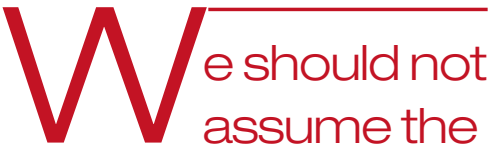

public will always agree, even if we do explain

\section{what we're doing.}

and white, but need to be addressed on a case-by-case basis (see http://www.oecd. org/subject/biotech/edinburgh.htm).

A subsequent e-mail conference, sponsored by the UN's Food and Agriculture Organization (FAO), on food production in developing countries, is open to all at biotechadmin @fao.org and has attracted 130 submissions from 19 countries, most in the developing world. Their overwhelming message, as in Edinburgh, is that the developing world needs and wants GM technology, but it must involve appropriate partnerships between the public and the private sectors.

The agrifood industries have now (not before time, given their enormous resources) taken two initiatives. Cropgen, a UK communications initiative comprised of a panel "from a variety of disciplines including the biological sciences and consumer affairs", is claimed to be independent from its sponsors, who "have all signed an undertaking not to veto any of the scientific positions or influence the activities of Cropgen". A similar initiative, sponsored by the Council for Biotechnology in the United States, is funded by seven agrifood companies and the Biotechnology Industry Organization, with a \$50 million budget over three to five years. Whether its advice will be considered 'objective' by the public remains to be seen.
A more hopeful source is the European Union, where Commissioner Philippe Busquin has just set up a biosciences highlevel group to give advice on the "scientific aspects of social controversies about biosciences and biotechnology" (see Nature $405,54 ; 2000)$. At the first meeting last month I was impressed by the commissioner's determination to bring in scientific advice at the highest level. We should do all we can to help this new initiative.

Does GM technology need a permanent forum to assess its science and the social implications, as suggested at Edinburgh (see Nature 404, 112; 2000)? One analogy, the Intergovernmental Panel on Climate Change, has been outstandingly successful, despite some criticism. But for GM foods, what is viable? How can all the stakeholders be involved, and under whose auspices: the $\mathrm{UN}$, the FAO, the WHO? Any such body must be open, transparent and inclusive. Is there enough international political will to make this work? I remain to be convinced.

For scientists in academic institutions, listening to the public — as advocated by the House of Lords (see http://www. publications.parliament.uk/pa/ld199900/ ldselect/ldsctech/38/3801.htm and Nature 404, 211; 2000) — is made easier by two e-mail information networks, one run by the Royal Society in London and the other by the University of Bern, to help those who are approached by the media.

Over the past two years the Royal Society has become more proactive, to help meet its objective of ensuring that policy decisions are based on sound science. It is working with six academies - the US National Academy of Sciences and five from less developed countries - to produce a statement on GM plants.

\section{Still trusted by the public}

The traditional inclination of academic researchers has been to comment on, but not to become directly involved in, public controversy. That is no longer enough.

Recent surveys show that scientists, as a group, still have the public's trust. Surely, therefore, we have a duty to help the public make decisions, particularly in areas where science is the subject of campaigns by environmentalist and other special-interest groups. Let's get to it!

Derek Burke is at 13 Pretoria Road, Cambridge CB4 1HD, UK. He is the former chairman of the UK advisory committee on novel foods and processes, and former vice-chancellor of the University of East Anglia. e-mail:dcb27@cam.ac.uk 